\title{
IDENTIFICATION OF SOME FIG INSECTS (HYMENOPTERA) FROM THE BRITISH MUSEUM (NATURAL HISTORY).
}

\author{
By Prof. Guido Grandi,
}

Portici, Italy.

Through the kindness of my friend Dr. James Waterston, the Authorities of the British Museum have sent me for examination a certain number of preparations containing some fig insects from various parts of the world. One of the species in this material, Otitesella digitata, Westw., has already been studied and figured by me in a recent paper ;* some of the others are dealt with below.

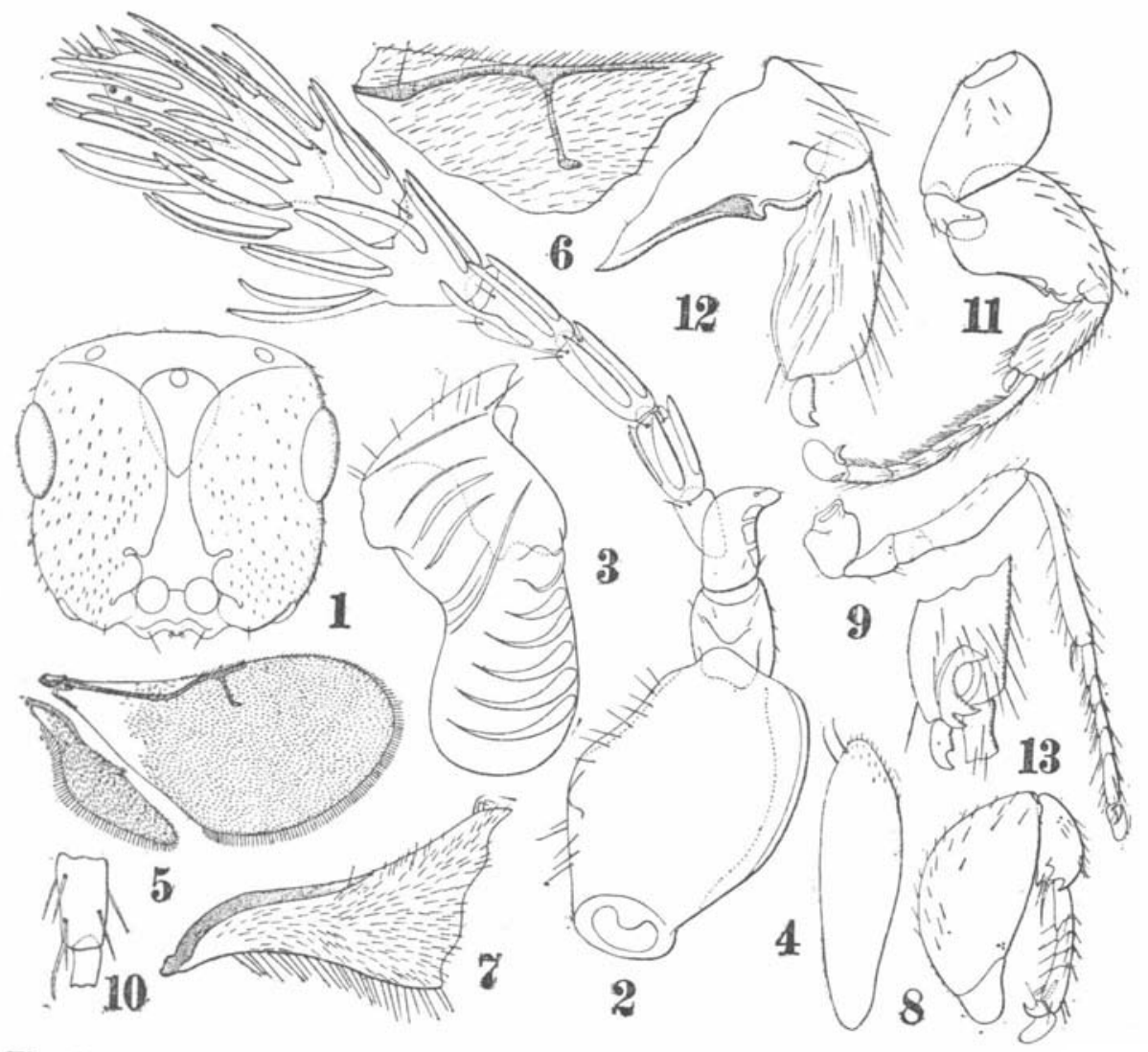

Fig. 1. Blastophaga quadraticeps, Mayr, $O$ : 1, head from in front, without antennae or mandibles; 2 , antenna ; 3 , ventral aspect of mandible ; 4, first maxilla; 5 , wings ; 6 , marginal vein and radius of fore wing; 7, proximal portion of hind wing; 8 , external view of fore leg, without coxa; 9, middle leg; 10 , distal extremity of tibia of middle leg; 11, hind leg from inner aspect ; 12 , distal portion of femur and tibia of hind leg, showing the special coadaptation; 13, external view of distal portion of hind tibia, showing subapical dentate process.

* Grandi, G.-Ricostruzione e morfologia comparata dei generi Otitesella, Westw., Sycobiella, Westw., ed affini.-Boll. Lab. Zool., Portici, xvi, 15 Aprile 1922, pp. 1-58, 21 figs. (v. pp. 18-21, figs. $i$ and ii). 
Blastophaga quadraticeps, Mayr.

Verhandl. d. K.K. zool. bot. Ges. Wien, B., xxxv, 1885, pp. 154, 161, 164, 176, 177.

ㅇ.-General body colour tawny brown, dark in various parts. Base of antennae and legs honey-coloured.*

Measurements. Length of head, $0.36 \mathrm{~mm}$. ; width, $0.36 \mathrm{~mm}$.; length of thorax, including propodeon, $0.64 \mathrm{~mm}$.; width of thorax, $0.45 \mathrm{~mm}$. ; length of abdomen, $0.70 \mathrm{~mm}$.; that of the free portion of the terebra, $0.96 \mathrm{~mm}$.; length of fore wings, $1.22 \mathrm{~mm}$; width, $0.56 \mathrm{~mm}$. ; length of hind wings, $0.71 \mathrm{~mm}$.; greatest width, $0.15 \mathrm{~mm}$.

Head. The epicranium (fig. $1,{ }^{1}$ ) is about as long as broad; its lateral margins in front of the eyes (taken between the mandibular fossae) are as long as, or a little longer than, the greatest diameter of the eyes and slightly convex. The epistomal edge shows a feeble angular median prominence and two rounded submedian projections. The median posterior chitinised area of the frons is rather limited and hardly reaches to the anterior ocellus. Bristles as in figure. Antennae (fig. $1,{ }^{2}$ ) with the scape about half as long again as its greatest width; third joint ending in a laminate process, strongly recurved, rounded off at the apex, and with some subquadrangular areas more strongly chitinised; fourth joint slightly longer than wide; fifth joint onehalf longer than the fourth and about twice its greatest width, with a few large elongate sensoria, which occupy almost its whole length and project slightly over its distal extremity; sixth slightly longer than the fifth and about equal in breadth, and with similar sensoria; seventh almost as long as the sixth, but about twice as broad at its distal extremity, some of its sensoria projecting slightly distally, others for one-third or half their length; eighth joint a little longer than the seventh but much wider distally, strongly contracted at base and provided with a certain number of sensoria, some of which occupy its whole length and project slightly over its apex ; others, very long, rising from a rather large base at the distal margin, project to a distance equal to once or twice the length of the joint; others extend along the joint for a certain distance and project strongly, though not so far as the preceding ones. The ninth and tenth joints similar to the eighth, though the ninth is a little longer than either the eighth or tenth, and with similar sensoria. The tenth subfusiform and provided with many long and projecting sensoria. Bristles very few and short, and distributed as in figure. Mandibles (fig. $1,{ }^{3}$ ) bidentate at the apex. The proximal process about as long as the body of the mandible, broadly rounded posteriorly, and with seven transverse ridges, the first (proximal) has a tooth-like appearance. Bristles as in figure. First maxillae (fig. 1,4) with a couple of rather short, normally-shaped distal, marginal bristles.

Thorax. Pronotum subtrapezoidal, with a few scattered hairs, scutum of the mesonotum almost bare ; scapulae with a submarginal external group of small bristles (six or little more) ; axillae with six to nine submarginal internal hairs; scutellum with very few (four or five) ; parascutelli bare. Metanotum with few small sublateral hairs.

Fore wings (fig. 1, 5, 6) about twice as long as broad and broadly rounded at the distal extremity; submarginal twice as long as the marginal and postmarginal; marginal almost as long as the postmarginal, which ends indistinctly; radius a little longer than the postmarginal vein and directed slightly obliquely towards the distal extremity of the wing and ending in an elongated dilatation with two sensoria. Costal cell about eight times as long as its greatest width and covered on its distal half with many small hairs. Hairs of the alar disc and fringe as shown in fig. $1^{5}$ and $^{6}$. Hind wings (fig. $1,{ }^{5}, 7$ ) a little longer than half the fore wings and about four times as long as broad, narrowing considerably at their distal extremity, where they become abruptly rounded. The neuration becomes indistinct at about half the distance between the

* Specimens mounted in Canada balsam. For names of colours see Saccardo (P. A.). "Chromotaxia." Patavii, 1912. 
base of the wing and the point of the costal margin, where there is a group of three hamuli. Bristles as in the figure.

Fore legs (fig. 1, 8 ) with the femur about twice as long as its greatest width ; tibia a little less than half the femur and provided on its external aspect with a tridentate process ; tarsus about one and a half times as long as the tibia, and its first joint half the length of the tibia; pretarsus and bristles as in figure. Middle legs (fig. 1, 9, 10) with the trochanter slightly shorter than the coxa, or about one-third the length of femur; tibia longer than femur and provided at the distal extremity of its ventral margin with a lancet-like spur which is one-sixth its length ; tarsus a little shorter than tibia ; second and third joint equal and a little shorter than the first ; fourth shortest of all; the fifth the longest; pretarsus and bristles as in figures. Hind legs (fig. 1, 11-13) : coxa as long as femur or slightly shorter ; femur with dorsal margin strongly convex and broadly rounded ; tibia just shorter than femur and provided with a very conspicuous compound tridentate armature situated at the distal extremity of its exterior aspect and with a sublaminar and bifid terminal spine (fig. 1, 11-13). The femur and tibia show a very interesting reciprocating mechanical arrangement. Towards the distal extremity of the ventral margin of the femur there is an angular projection strengthened by a chitinous thickening, which is prolonged proximally, thinning out beyond the middle of the femur and running in a submarginal direction. This projection is followed by an abrupt concavity of the margin and then by a round process. The tibia in the proximal half of its ventral margin has a rounded projection, limited proximally and distally by two slight convexities (fig. 1, 12). Tarsus twice as long as the tibia; the length of the first joint equal to three-quarters that of the tibia and of the free ventral margin of second, third, and fourth joints taken together; fourth joint shortest of all ; fifth about as long as the second ; pretarsus and bristles as in figure.

Abdomen. Urotergites sparsely pilose. Cercoids of the ninth urotergite with four bristles, which are longer than the appendage, one of them being twice as long. Projecting portion of terebra a little less than one and a half times as long as the abdomen.

Geographical distribution. Three specimens mounted in Canada balsam from Ceylon, collected by Dr. Thwaites in the receptaculi of Ficus religiosa, forming part of the material examined by Westwood, who says, on p. 43 of his " Further Descriptions of Insects infesting Figs" (Trans. Ent. Soc., London, 1883, pp. 29-47) : "1. Both sexes of a species of Blastophaga, of which the antennae of the female are strongly clavate, with the terminal joints armed with very strong compressed bristles."

Observations. Mayr's material came from Singapore, and was collected by Count Solms-Laubach. This author's description of the $Q$ is very superficial.

\section{Blastophaga williamsi, sp. $\mathrm{n}$.}

․ Colour of body smoky-brown. Antennae from the fifth joint honey-brown. Mandibles ferruginous. Legs honey-coloured, more or less infuscated.

Measurements. Length of head, $0.33 \mathrm{~mm}$. ; width, $0.35 \mathrm{~mm}$.; length of thorax, including propodeon, $0.60 \mathrm{~mm}$. ; length of abdomen, $0.57 \mathrm{~mm}$. ; length of projecting portion of terebra, $0 \cdot 50-0.60 \mathrm{~mm}$. ; width of the peritremes of the tracheal spiracles of the eighth urotergite, $0.035 \mathrm{~mm}$.

Head (fig. 2, 1) a little wider than long and slightly developed behind the compound eyes; its lateral margins in front of the eyes equal in length to the greatest diameter of the eyes and rather converging anteriorly. The epistomal edge with a median angular and two submedian broadly rounded prominences; eyes moderate, subposterior, three ocelli placed on the vertex in a very obtuse triangle; hairs and bristles as in figure. Antennae (fig. 2, 2,3) of eleven joints, of which the last three form the club. Scape about one and a half times as long as its greatest width ; second joint as in figure; the third divided into two parts, one proximal, somewhat ring-like, 
and the other distal, laminate, which thins out at its apex and ends in a small toothlike spike ; fourth joint twice (or a little less) its distal width ; fifth joint about as long as the fourth and as long as broad; sixth, seventh, and eighth equal, but increasing slightly in width ; the sixth exactly as long as wide, the eighth wider than long; all these three distinctly larger than the fifth; the ninth and the tenth just transverse and as wide as the eighth ; the eleventh longer than broad and somewhat spindle-shaped. All the joints from the fifth to the tenth have, besides various rather long and strong bristles, a certain number of large and long sensoria, which are almost as long as the joints themselves and project rather conspicuously beyond their distal extremities. Mandibles (fig. 2, 4) bidentate, with the apical tooth projecting and acute; ventral surface with about a dozen ridges, transversely obliquely arranged. The proximal process about as long as the mandible, with eleven transverse raised laminae ; the first (proximal) has a tooth-like appearance; bristles as in figure.

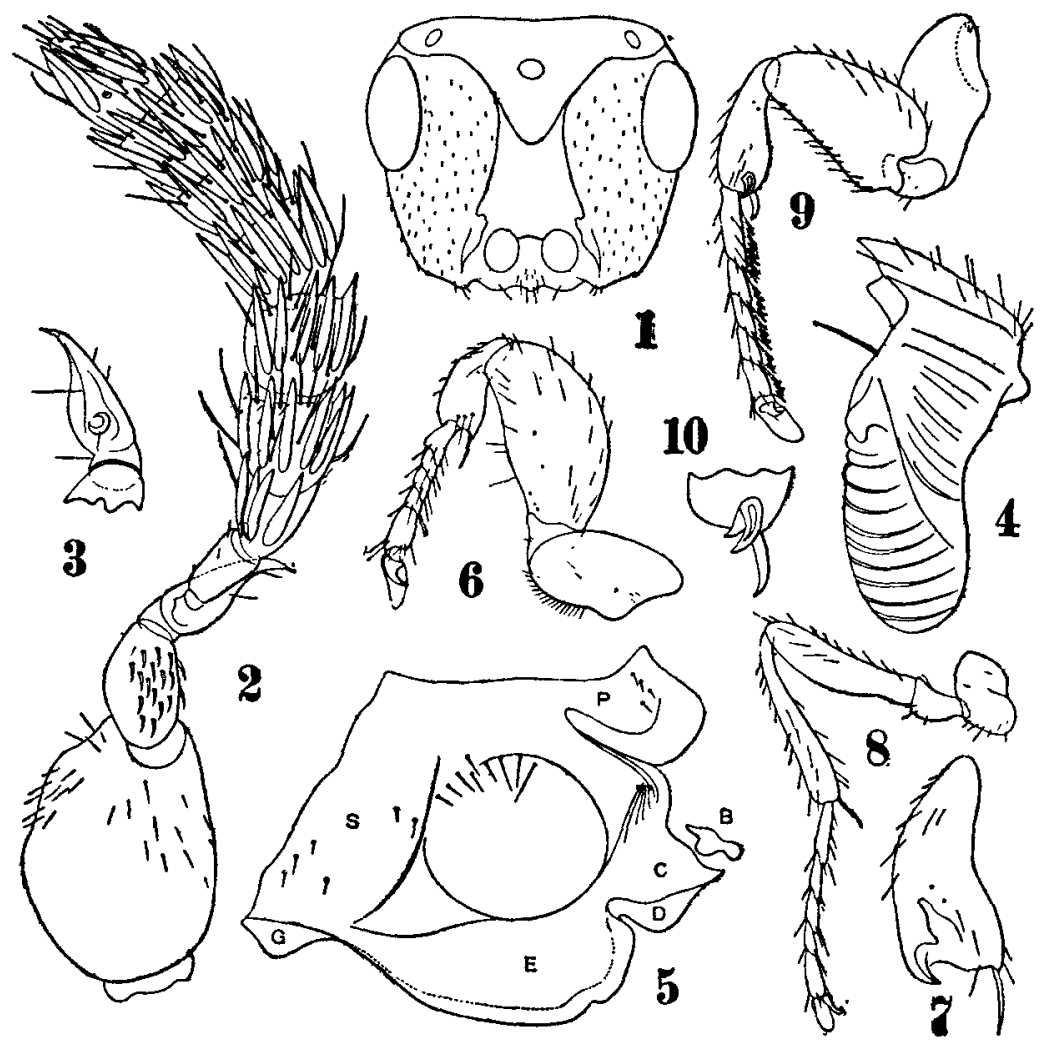

Fig. 2. Blastophaga williamsi, Grandi, $q$; 1, head seen from in front, without antennae or mandibles; 2, antenna; 3 , third joint of antenna and distal extremity of second; 4, ventral aspect of mandible; 5 , left half of sternopleural mesothoracic region ( $B$, posterior basal sclerite : $C$, mesopleural alar process; $D$, marginal expansion of mesopleura corresponding to epimeral region; $E$, epimeral region; $G$. mesosternal leg-bearing condyle; $P$, prepectus; $S$, stemal region); 6, front leg (inside) ; 7 , tibia of front leg (outside); 8 , middle leg ; 9 , hind leg; 10 , distal extremity of tibia of hind leg.

Thorax. Pronotum sparsely pilose. Anterior portion of mesonotum strongly transverse. Scutum bare; scapulae with a few small submarginal, lateral, external hairs. Scutellum with a submedian irregular group of about fifteen minute bristles; axillae with three or four hairs along their internal margin; parascutelli bare and larger than axillae. Sterno-pleural mesothoracic region as in fig. $2,5$. 
Fore legs (fig. 2, ${ }^{6.7}$ ) with the coxa a little less than twice as long as broad; femur slightly less than one and a half times the coxa; tibia half the length of the femur, and provided with an external bidentate expansion and a simple spiniform spur. Tarsus one and a half times as long as the tibia; its first joint about as long as half the tibia and like the fifth; its free ventral margin equal in length to that of the three following joints taken together. Pretarsus and bristles as in figure. Middle legs (fig. 2, ${ }^{8}$ ) with the coxa transverse; trochanter about one-third of femur, which is slightly shorter than tibia; the latter a little shorter than the tarsus and provided with a rather long and spiniform spur. The first joint of tarsus as long as the two following taken together; the fifth as long as the second. Pretarsus and bristles as in figure. Hind legs (fig. 2, 9, 10) with coxa about as long as femur and longer than tibia; the latter provided at its distal extremity with a tridentate complex and a simple tooth-like spur. Tarsus one and a half times as long as tibia; its first joint little longer than half the length of tibia and the following two joints taken together. Pretarsus and bristles as in figure.

Abdomen. The urotergites with a certain number of short hairs irregularly arranged; the cercoids of the ninth urite with four relatively long bristles each. The projecting portion of the terebra a little longer than the abdomen.

Geographical distribution.-A dozen $\circ 9$, mostly mutilated, devoid of wings and mounted in Canada balsam; collected by C. B. Williams in Barbados on the 19th April 1915.

Observations.-This species, so far as one can judge from the insufficient and incomplete description of Mayr and without the help of the characters of the male, approaches very closely B. brasiliensis, Mayr, and B. bifossulata, Mayr, from Brazil. From the first, however, it would appear to differ in the distinctly shorter terebra $(0 \cdot 58-0.68 \mathrm{~mm}$. instead of $0 \cdot 80-0.84 \mathrm{~mm}$.) and the first joint of the fore tarsus, which is half the length of the tibia and not one-third; from the second species in the fourth joint of the antennae, which is twice as long as broad distally (instead of being as long as wide) and in the first joint of the tarsus, which in the Brazilian form is scarcely one-fifth the length of the tibia.

\section{Coratosolen fuscipes, Mayr.}

Mayr, Verh. zool. bot. Ges. Wien, xxxv, 1885, pp. 161, 163, 167, 168, pl. xi, fig. 3 ; Grandi, Boll. Lab. Zool. Portici, xi, 1916, pp. 194-201, figs. v-viii.

Six $\$ 9$ mounted in Canada balsam and collected by Prof. H. M. Lefroy in India. This species was already known in Java and Ceylon. In the latter island it is found in the receptaculi of Ficus glomerata, Roxb. Mayr mentions having examined some specimens collected in Java in Ficus covellii.

The terebra of the 99 belonging to the British Museum is a little longer than the abdomen or, rather, somewhat longer (length of gastrum, $0.96 \mathrm{~mm}$.; length of projecting portion of terebra, $1.22 \mathrm{~mm}$.) but is never one and a half times as long as the abdomen.

\section{Coratosolen crassitarsus, Mayr.}

Mayr, Verh. zool. bot. Ges. Wien, xxxv, 1885, pp. 161, 163, 171, 172, pl. xi, fig. 7 ; Grandi, Boll. Lab. Zool. Portici, xii, 1917, pp. 40-46, figs. xiv, xv.

One $q$ and six $\sigma^{\star} \sigma^{*}$ mounted in Canada balsam and collected by $H$. N. Ridley in Singapore, Malay Peninsula, occurring in Ficus roxburghi. This species was known from the island of Java, where it is found in the receptaculi of Ficus ribes, Reinw.

In the British Museum specimens the first joint of the fore tarsus of the $q$ is longer than the following three taken together; in the $\sigma^{\pi}{ }^{\pi}$ the tibia of the middle leg is provided at the distal extremity with four spiniform teeth, the internal one of which is very conspicuous. 